\section{Regionalismo, modernidade e legitimidades intelectuais: Moysés Vellinho e Érico Veríssimo (1930 a 1964)}

\section{Regionalism, modernity, and intellectual legitimacy: Moysés Vellinho and Érico Veríssimo (1930 to 1964)}

RODRIGUES, Mara Cristina de Matos. Regionalismo, modernidade e legitimidades intelectuais: Moysés Vellinho e Érico Veríssimo (1930 a 1964). História, Ciências, Saúde Manguinhos, Rio de Janeiro, v.17, n.4, out.-dez. 2010, p.993-1008.

Resumo

Busca-se compreender como o crítico literário Moysés Vellinho se inseriu no processo de afirmação de legitimidades intelectuais no contexto cultural marcado pelo par 'província-nação', comparando-se sua atuação com a de Érico Veríssimo entre 1930 e 1964 . Os personagens foram escolhidos em virtude de seu protagonismo no cenário cultural local e brasileiro no período. Examina-se o sentido dos textos e o lugar social que os produziu: uma sociedade confrontada simultaneamente com a institucionalização universitária e a especialização incipiente das humanidades, a expansão do mercado de literatura e a releitura do regionalismo sul-rio-grandense.

Palavras-chave: intelectuais; historiografia; regionalismo; Rio Grande do Sul.

\section{Abstract}

The article compares the roles that literary critic Moysés Vellinho and author Érico Veríssimo played in affirming intellectual legitimacy in a period when the Brazilian cultural context was marked by the notion of 'province-nation,' focusing on 1930 to 1964. These two figures were chosen because they were protagonists on both the regional and national cultural stages during this time. The meaning of their texts is examined against the backdrop of the social space that produced them: a society that was witnessing both the institutionalization of the university and the start of specialization within the humanities, as well as the expansion of the literature market and the re-interpretation of Rio Grande do Sul regionalism.

Keywords: intellectuals; historiography; regionalism; Rio Grande do Sul (Brazil). 
$\mathrm{S}$ egundo Letícia Nedel (2005) e Odaci Coradini (2003), entre as décadas de 1920 e 1960 operou-se, no cenário intelectual do Rio Grande do Sul, uma rediscussão dos critérios definidores do gaúcho como tipo sociocultural e, concomitantemente, do regionalismo como categoria classificatória da literatura e de outras produções letradas, como a historiografia. Em lugar da restrição da identidade local ${ }^{1}$ à figura do homem da campanha gaúcha, buscava-se incluir, no espectro da representação sociocultural do sul-rio-grandense, outros atores sociais vinculados material e simbolicamente ao cenário urbano, em especial os escritores. Assim, pode-se dizer que as "revisões semânticas do gaúcho se referem, empiricamente, às lutas travadas no interior do espaço local e nacional de atuação cultural" (Nedel, 2005, p.233; grifo do original).

De forma complementar, neste trabalho busca-se compreender como Moysés Vellinho (1901-1980) se inseriu nesse quadro em que se empreendeu a afirmação das legitimidades intelectuais referidas ao contexto cultural 'província-nação', comparando sua atuação intelectual com a de Érico Veríssimo (1905-1975), seu contemporâneo. A escolha das trajetórias e das representações histórico-regionais desses personagens como foco da investigação se justifica em virtude do protagonismo que eles desempenharam no cenário cultural local e brasileiro entre os anos 1930 e 1960. O segundo, como se sabe, adquiriu notoriedade nacional como romancista nesse período ${ }^{2}$ e dispensa apresentação. O primeiro - que foi crítico literário da década de 1920 até a de 1950, e historiador desde a década de 1950 até a de 1970 -, a despeito de não ter obtido destaque comparável ao de Veríssimo, participou ativamente dos embates locais sobre o regionalismo, a literatura, a identidade e a história sul-rio-grandenses. Integrava-se também às redes de sociabilidade que conectavam a atuação local aos espaços de concorrência e consagração mais amplos da intelectualidade brasileira. Além disso, ocupou posições destacadas nas instituições políticas do estado sulino desde a década de 1920, e notabilizou-se no grupo sul-rio-grandense que apoiou a Revolução de 1930, tornando-se eventualmente figura controvertida e polêmica, mas sempre influente no cenário intelectual regional. Era, junto com Veríssimo e outros intelectuais de sua geração, um dos porta-vozes autorizados da 'província'.

Os pressupostos teóricos e metodológicos deste trabalho conduzem a análise pelo cruzamento de duas abordagens nem sempre associadas: a história intelectual e cultural inspirada nas categorias sociológicas e a história da historiografia de cunho hermenêutico. Enquanto a primeira tem enfocado as problemáticas do meio intelectual, muitas vezes priorizando sua vinculação com a política partidária e as ideologias políticas ${ }^{3}$, a segunda opta por maior atenção ao texto produzido pelo escritor ${ }^{4}$, o que não inviabiliza, neste caso, uma atenção a dimensões do trabalho intelectual às vezes denominadas 'extratextuais' (Chartier, 2002). ${ }^{5}$ Mesmo assim, não raro torna-se difícil atentar simultaneamente para os liames entre, por um lado, o sentido produzido no e pelo texto e, por outro, as condições sociais e intelectuais de produção, em especial quando se trata de análise concomitante das trajetórias e das estratégias narrativas de produção de sentido de toda uma geração de intelectuais. Esses problemas de ordem metodológica nem sempre se restringem a filiações teóricas, estando muitas vezes limitados pelas próprias condições de produção da pesquisa, como a existência de estudos anteriores qualificados sobre o tema. Neste trabalho, partindose do cruzamento daquelas perspectivas delineadas de abordagem do passado e dispondo-se 
de importantes trabalhos precedentes ${ }^{6}$, pretende-se honrar a assertiva clássica de Michel de Certeau (2002) em relação ao ofício do historiador, considerando as representações do passado referidas a sua dimensão textual, prática (disciplinar) e a seu lugar social de produção.

Contudo, se for levantada a objeção de que se trata de uma 'operação historiográfica' (mais sociológica do que historiográfica) em Moysés Vellinho e de uma escrita 'literária' em Érico Veríssimo, cabe ressaltar que o paralelo entre ambas se justifica pela então precária especialização desses gêneros de escrita, em relação aos moldes atuais. A tradição letrada do ensaio histórico-sociológico vigorava no Brasil desde o final do século XIX, constituindose como possibilidade formal de representação do passado, opção teórica privilegiada principalmente fora das universidades, em processo recente de institucionalização. $\mathrm{O}$ ensaio configurava-se assim como um 'lugar epistemológico' das humanidades, no qual as preocupações acadêmicas associavam-se a um estilo literário de escrita. ${ }^{7}$ Além da aproximação formal das duas modalidades de escrita, no caso de que trata este artigo verifica-se também que, entre o ensaio histórico-sociológico de Moysés Vellinho e a literatura de Érico Veríssimo, há confluência de projetos culturais e problemáticas históricas. ${ }^{8}$

Entre as décadas de 1930 e 1960 as estratégias de inserção dos intelectuais sul-rio-grandenses no âmbito da produção cultural em processo de especialização e normatização deviam levar em conta a ampliação do mercado editorial que se operou nesse período, pari passu com a que ocorria no centro do país (Miceli, 1979, p.69-128). Vellinho, Veríssimo e toda uma geração de intelectuais gaúchos estavam, dessa forma, confrontados tanto com um cenário particularmente favorável à circulação das proposições romanescas e historiográficas que abrasileiravam a cultura do estado, tornando-a mais palatável a um público que excedia o regional e não se restringia ao círculo erudito, quanto com o aumento da concorrência decorrente dessa ampliação de mercado. Assim, de acordo com essa configuração do quadro da produção cultural e intelectual no Rio Grande do Sul e com cuidadosa leitura dos escritos dos autores aqui considerados, em suas perspectivas a principal 'conquista' a ser empreendida pelos gaúchos de meados do século XX não seria mais a de fronteiras, territórios e mercados para os produtos agropecuários da região, como no século XIX, ou a de postos políticos no governo central do país, como na Revolução de 1930, mas sim a de mercados mais ampliados para os produtos culturais do extremo sul brasileiro.

\section{Moysés Vellinho e Érico Veríssimo nos anos 1930: o 'estabelecido' e o outsider ${ }^{9}$}

Enquanto Moysés Vellinho iniciou no métier intelectual escrevendo polêmicos textos de crítica literária para os jornais da capital na década de 1920, Veríssimo inauguraria sua carreira de escritor com a publicação de um livro de contos na Editora do Globo, no início dos anos $1930 .{ }^{10}$ De saída, é preciso estabelecer uma distinção quanto aos recursos sociais e políticos de cada um: o romancista vinha de família tradicional do interior do estado, mas arruinada financeiramente, e tinha participado de experiência malsucedida no ramo comercial. No seu primeiro encontro, o boticário falido buscou, à moda tradicional daqueles anos, um emprego público junto ao já bem estabelecido Moysés Vellinho. Suas idades eram muito próximas: Érico nascera em 1905, apenas três anos depois de Vellinho. Assim, 
a assimetria social entre eles relacionava-se, sobretudo, a capitais sociais e escolares diferenciados e não a defasagem cronológica de suas carreiras, pois, apesar de ambos terem nascido no interior do estado e estudado na capital, Érico fora obrigado a interromper seus estudos como interno no colégio anglicano Cruzeiro do Sul, em virtude da bancarrota familiar, ao passo que Vellinho concluíra o ensino básico no Colégio Anchieta - uma das mais prestigiadas escolas do Rio Grande do Sul - e o curso superior na Faculdade de Direito de Porto Alegre. Em suas memórias, Veríssimo representa essa diferença de estatuto social ao relatar o evento referido, quando chegava a Porto Alegre vindo de Cruz Alta:

\footnotetext{
Mesmo assim, em desespero de causa, andei por mais de uma secretaria de Estado em busca de emprego. Na do Interior tive a oportunidade de conhecer pessoalmente Moysés Vellinho, então chefe do gabinete de Oswaldo Aranha. Era crítico literário e escrevia sob o pseudônimo de Paulo Arinos ...

Diante daquele homem insinuante, de maneiras tão finas e impecavelmente vestido, experimentei um sentimento de inferioridade parecido com o que me assaltara tantas vezes no internato nos fins de semana, quando eu olhava para as roupas de meus colegas trajados no rigor da moda e comparava-as com o meu 'fardamento' de mandim serrano.

Vellinho declarou-me que infelizmente no momento não havia vagas naquela secretaria (Veríssimo, 1995, p.235).
}

A distância entre os dois intelectuais, naquele momento, pautava-se principalmente pelas condições financeiras superiores de Moysés Vellinho, o que foi bem demarcado por Veríssimo no contraste entre suas vestimentas. Mas também se veem claramente as possibilidades vantajosas que se apresentavam para o indivíduo bem e longamente estabelecido na capital, em relação ao outsider recém-chegado do interior do estado. ${ }^{11}$ Vellinho representava a típica carreira de sucesso para um homem de pretensões intelectuais no Brasil do início da década de 1930: ocupava importante cargo junto a um dos políticos de maior destaque no estado e já se inserira no mundo intelectual, no grupo da Livraria do Globo (Coradini, 2003), escrevendo crítica literária para os jornais mais importantes da capital. Como estratégia de inserção no campo cultural, no início de sua carreira, utilizouse da polêmica para se destacar, ajustando sua mira contra o regionalismo do imortal Alcides Maya, em 1925, sob o pseudônimo de Paulo Arinos. Chamou a atenção dos pares ao debater nas páginas do Correio do Povo com Rubens de Barcellos, reconhecido intelectual porto-alegrense que se alinhou na defesa da obra do insigne escritor. ${ }^{12}$ Nesse sentido, cabe perguntar como Veríssimo pôde alçar-se à posição de grande escritor brasileiro em poucos anos a partir dessa data, se não obteve sucesso ao tentar seguir o caminho tradicional da lide intelectual à sombra de um emprego público ou de um grande político.

Após o momento inicial de proximidade física e distanciamento social, os rumos tomados pelos dois intelectuais ampliariam o afastamento estrutural das posições sociais ocupadas por cada um, transformando-se em modalidades distintas de inserção no campo cultural. Isso ocorreu ainda no início da década de 1930, quando Moysés Vellinho partiu, juntamente com Mansuetto Bernardi e outros intelectuais gaúchos, para o Rio de Janeiro, a fim de ocupar as posições políticas abertas pela 'Revolução' aos agentes habilitados, nas áreas periféricas da nação. Nessa saída da província, deixaram espaços vagos no âmbito da atuação cultural para aqueles que não dispunham de capital social e político para 
acompanhar Vargas em sua ascensão ao poder central. Foi assim que, após a negativa de Moysés Vellinho ao emprego pleiteado por Veríssimo, o futuro romancista ingressou nos quadros da Livraria do Globo, para substituir Mansuetto Bernardi na direção da recémcriada Revista do Globo (Veríssimo, 1995).

Durante o período em que Vellinho trabalhava junto ao ministro Oswaldo Aranha no Rio de Janeiro, Veríssimo se ocupava da nova posição profissional. Marisa Lajolo (1986, p.167) sintetiza muito bem as atividades do escritor naquele momento, sugerindo a importância dessa experiência para a compreensão da singularidade de sua trajetória nos anos seguintes:

Foi, pois, empunhando galhardamente a tesoura e o pote de cola que Érico começou produzindo a revista cuja direção assumiu em 1932. Era como um aprendiz humilde que Érico fazia a Revista do Globo, escrevendo editoriais, engordando-a com traduções, espichando-a com os desenhos que surrupiava de revistas estrangeiras, improvisando textos para tais ilustrações, compondo poemas-relâmpago para preencher os espaços em branco, tudo por um salário de 600 mil réis. No prosaísmo desse aprendizado, Érico parece ter vivido situações que talvez expliquem a radical dessacralização com que, ao longo de sua vida, ele produz e discute livros e literatura.

Dessa forma, como responsável pela confecção artesanal de uma revista que deveria ter sucesso comercial, Veríssimo angariou a confiança do empresário Henrique Bertaso, entrando em contato com as sensibilidades de um público provinciano de classe média e com as metas comerciais de uma empresa que ambicionava extrapolar os limites do mercado regional.

\section{O retorno do 'estabelecido' e o estabelecimento do outsider}

Enquanto Veríssimo mergulhava no universo literário, mercadológico, moderno e artesanal da Editora do Globo, Vellinho voltaria ao Rio Grande do Sul ainda na década de 1930 para viver seu momento de maior envolvimento com a política partidária, quando integraria os quadros da dissidência liberal que defendeu o governo provisório de Vargas da oposição de Flores da Cunha (Vellinho, 1981a). Veríssimo, seguindo rumo quase oposto, autonomizou-se economicamente como escritor ao lançar Olhai os lírios do campo, em 1938. Entretanto, no mesmo momento em que o escritor podia desfrutar de situação rara no contexto regional e nacional, isto é, obter seu sustento na literatura, tornava-se, por isso, suspeito aos olhos de parte da crítica literária do centro do país. Seus romances, até então, tratavam de temáticas urbanas e modernizantes, distanciadas a todo custo dos motivos regionalistas (Veríssimo, 1995, p.288), o que lhe granjeava a abertura de um mercado consumidor ansioso pela problematização das inquietantes transformações sociais e culturais do processo de modernização no país. Por outro lado, o sucesso editorial custou-lhe não apenas a desconfiança da crítica do centro do país, que duvidava da qualidade de uma literatura muito vendável, mas também a da crítica local, que esperava encontrar elementos mais tradicionalmente associados ao 'caráter' do Rio Grande do Sul, representados nos textos literários dos escritores gaúchos. ${ }^{13}$

O paralelo das duas trajetórias revela, até aqui, que no mesmo momento em que Veríssimo e a Livraria do Globo desfrutavam de sucesso estreitamente vinculado à ampliação do 
mercado regional para a literatura traduzida ou elaborada no Rio Grande do Sul, a trajetória de Vellinho, até então vinculada prioritariamente às boas relações políticas de que desfrutava, tendia cada vez mais a desvinculá-lo da atividade intelectual e a estreitar suas relações com a carreira político-partidária. Posteriormente, contudo, Vellinho definiu esse momento como de gradual desencanto com os rumos do Estado Novo e com a atuação de Getúlio Vargas no governo federal. Em depoimento da década de 1970, buscava demonstrar, nesse contexto de sua participação política mais ativa, o crescimento silencioso de suas diferenças em relação ao governo instituído e a progressiva conversão de suas energias para o trabalho intelectual (Vellinho, 1981a, p.29). Essa mudança de perspectivas e atuação no campo político acabou proporcionando progressiva semelhança entre alguns aspectos de sua trajetória intelectual e a de Veríssimo. Nas memórias do romancista, o segundo encontro com Moysés Vellinho foi representado de forma bem distinta do primeiro:

\footnotetext{
No verão de 1939-1940 nossa situação financeira nos permitiu passar duas semanas na verde e fresca paz de Gramado, na chamada zona colonial. Um dos saldos positivos desse veraneio foi a oportunidade que tive de conhecer mais de perto Moysés Vellinho, que lá se encontrava com a família. Apesar de minha admiração e respeito intelectual pelo escritor, eu tinha a impressão de que como pessoa ele era um esnobe, pobre de vibração humana. O convívio de alguns dias me convenceu exatamente do contrário. Fiz mentalmente uma errata: onde se lê esnobe, leia-se discreto (Veríssimo, 1995, p.270; grifos do original).
}

Depois do (des)encontro da década de 1930 entre o ex-boticário desempregado e o burocrata esnobe, e da gradativa identificação entre eles, cabe destacar-lhes a reação ao golpe do Estado Novo, ambos inicialmente favoráveis, como declarou Vellinho mais tarde. "À vista da crise geral das democracias", encarou o golpe de estado como mal necessário, sem 'repugnância', e saiu da política partidária ao aceitar, em troca de sua atuação na dissidência liberal, o cargo do Tribunal de Contas da União no qual permaneceria até sua aposentaria, na década de 1960 (Vellinho, 1981a, p.32). Veríssimo, a despeito de sua reconhecida aversão aos totalitarismos ${ }^{14}$, surpreendentemente posicionou-se, no calor da hora, de forma semelhante a Vellinho (Gertz, 2000, p.204), para logo a seguir rejeitar ostensivamente o novo regime. Em 1941 começou a escrever mais um romance urbano, O resto é silêncio, que acabou sendo o estopim de sua saída do Brasil por dois anos (Veríssimo, 1997b). A polêmica pública contra um padre jesuíta e outros elementos ligados à Igreja católica rendeu-lhe um processo judicial, manifestos publicados na grande imprensa sulina e mobilização da renovada aliança da Igreja católica com o governo federal (Trindade, 1984). Segundo suas memórias, esse episódio esgotou sua paciência com o autoritarismo vigente e foi o principal motivo para aceitar o convite do governo dos EUA para convênio cultural naquele país durante dois anos (Veríssimo, 1995). Talvez a experiência dessa viagem ${ }^{15}$ tenha tido papel ainda insuspeito na elaboração de $O$ tempo e vento, já que esse projeto era acalentado ao menos desde 1939, mas postergado em prol de assuntos como a ascensão do fascismo e do comunismo na Europa (p.287-289).

Enquanto Veríssimo encontrava-se nos EUA, em 1944 o ex-deputado estadual rompia definitivamente com Getúlio Vargas e redirecionava visivelmente suas energias às atividades intelectuais (Vellinho, 1981a). Segundo Moreira (1986), o primeiro crítico literário 
importante a analisar a obra de Veríssimo foi Moysés Vellinho, em ensaio na coletânea intitulada Letras da província (Vellinho, 2001a). Apesar de considerar promissora a carreira de Veríssimo, apontou o "excesso de técnica" e a "falta das raízes culturais" do escritor em seus romances, referindo-se evidentemente à temática privilegiadamente urbana, reconhecida pelo próprio romancista ao comentar a inclusão, em Olhai os lírios dos campos, de um improvável arranha-céu na provinciana Porto Alegre de 1938 (Veríssimo, 1995, p.288). Entretanto, se Vellinho esperava encontrar a autenticidade (rural) da região sulina representada na escrita literária sul-rio-grandense, propunha uma revisão do conceito de gaúcho e do regionalismo, ao reiterar, em outro ensaio da mesma obra, sua rejeição à vertente regionalista encabeçada por Alcides Maya (Vellinho, 2001a, p.86).

Assim, mesmo que prescrevesse a relação entre a literatura e as raízes culturais, Vellinho reconhecia a inadequação da representação tradicional à realidade que vivia em 1944. Sem negar a herança militar, guerreira e rural do gaúcho sul-rio-grandense, que explicaria as dificuldades históricas enfrentadas para o florescimento das atividades do pensamento, da erudição e da literatura, propunha que no tempo presente as armas dos guerreiros teriam cedido espaço à pena do poeta. Não se tratava mais de defender a legitimidade da liderança política gaúcha da nação nas representações da sociedade local - como no final dos anos 1920 -, mas, primordialmente, de reivindicar que o sangue ali derramado nos tempos heróicos da consolidação das fronteiras nacionais fosse considerado salvo-conduto para a abertura de espaço simbólico e mercadológico 'além-província' para os intelectuais dos novos tempos. Se isso não fosse possível, propunha, ao menos, a tolerância da crítica literária do centro do país com o tradicionalismo da literatura local, conforme declara ao comentar a crítica de Afonso Arinos ao conservadorismo linguístico dos escritores sulinos:

Convém não esquecer, com efeito, que estamos situados nas "fronteiras corruptíveis do idioma". Em arte, como no mais, é difícil nos explicarmos fora das funções de vigilância que as conjunturas históricas nos impuseram. A fatalidade nunca permitiu que a tensão política originada pela nossa posição de fronteiros cedesse à voluptuosa atração do sentimento cósmico ... O sangue que se verteu ali despertou uma consciência preventiva que nos arma contra as disposições de puro abandono às forças elementares da paisagem ... era preciso resguardar, além da integridade territorial do país, e com os demais componentes de afirmação cultural, a inviolabilidade do idioma originário em suas vigas mestras (Vellinho, 1946a, p.6).

Esse excerto representa a reivindicação da continuidade entre dois tempos e dois atributos morais aparentemente remotos: em primeiro lugar, continuidade entre o tempo das lutas fronteiriças, da formação da sociedade, e o da contemporaneidade; em segundo lugar, interliga o atributo do guerreiro do passado perante seu inimigo platino e o do escritor do presente confrontado com as escolhas no campo linguístico. Cabe lembrar que, em Vellinho, a proposição de legitimar o presente da escrita pelo passado de glórias militares aparece de forma mais evidente do que em Veríssimo, e não apenas em seus textos críticos, mas sobretudo na direção de um empreendimento marcante na história intelectual do Rio Grande do Sul: a revista Província de São Pedro, publicada entre 1945 e 1957, pela Editora do Globo. ${ }^{16}$

Considerando-se apenas as temáticas dos artigos publicados nessa revista, a coerência entre a defesa da legitimidade do intelectual da província e esse empreendimento editorial 
não fica evidente. Essa conexão fica mais clara com a leitura paralela dos editoriais e dos 'paratextos' - pequenos textos publicados em pés de página na revista, com referências elogiosas de jornais do centro do país ou mensagens recebidas de grandes nomes do cenário intelectual nacional, como por exemplo Sérgio Milliet, felicitando os organizadores da revista pela qualidade de seu empreendimento: "Província de São Pedro marca, pelo seu admirável esforço e o seu alto valor literário, a afirmação da intelectualidade provinciana no cenário nacional. Com 'provinciana' não quero dizer 'limitada', mas sim a presença do torrão natal fecundo e sólido, em oposição ao cosmopolitismo urbano" (Milliet, 1946, p.14).

A simples preocupação em divulgar, na revista, esses comentários demonstra a necessidade de afirmar o estreitamento de laços que se estabelecia, via iniciativa 'cultural' sul-riograndense, com as instituições e os autores mais importantes no cenário nacional. O editorial do primeiro aniversário da publicação sintetiza o significado dessa recepção nacional como parte primordial de seus objetivos e vale a longa transcrição a seguir. Nela, Vellinho explicita a relação entre a necessidade da releitura do regionalismo local, eivado de excessos, e a transformação da imagem simbólica do estado no todo nacional, mais adequada às necessidades de circulação de sua produção cultural:

\footnotetext{
Mas já que o nosso itinerário busca outros fins que não o de tomar contas aos nossos maus guias [políticos], cingimo-nos à observação de que em nossas práticas literárias, escritas ou faladas, nem todos se guardam de excessos na exaltação de sua província. São os que se enfunam de grandes adjetivos, soltam seus pendões ao vento, e passam a viver na falsa atmosfera que a fantasia verbal lhes oferece ... O pior é que a exacerbação regionalista, assim inconsiderada, despertava à distância, suspeitas, mal-entendidos ... O tom cauteloso de nossa carta de apresentação, em sua "disposição meio forense de argumentar e de defender-se", foi objeto de especiais comentários por parte de um dos jornais de São Paulo. Mas prova de tínhamos razão é que a folha a que aludimos não se perdeu no reparo, pois nenhum órgão da imprensa brasileira a excedeu na compreensão dos nossos propósitos nem no louvor à iniciativa que inspirou a Livraria do Globo no lançamento da Província de São Pedro. Esse gesto de simpatia cultural nos respondeu de todos os pontos do Brasil com um calor que é o prêmio mais alto a que podíamos aspirar. Vozes gratas nos vêm chegando ainda de longe, portadoras de manifestações as mais estimulantes. São críticos e jornalistas, poetas e escritores, sociólogos e romancistas - do Rio, de São Paulo, de Minas, da Bahia, de Pernambuco, do Paraná, do Ceará - a nos distinguirem com o seu aplauso, a sua solidariedade, a sua colaboração indispensável. Damo-nos por bem pagos (Vellinho, 1946b, p.5-6; grifos meus).
}

No periódico conviviam poemas, contos, ensaios de crítica literária, históricosociológicos, etnográficos, notícias dos eventos culturais mais importantes da capital sulrio-grandense, discussões acerca da etimologia dos regionalismos e da origem de certas tradições e lendas do folclore local, sem unidade formal e temática nem especialização disciplinar. Essa diversidade, entretanto, deve ser compreendida como parte da elaboração de um panorama genérico da cultura local, para ser dada a conhecer ao público letrado de todo o país. A unidade e a coerência desse estranho conjunto de trabalhos eram conferidas pelo local de origem das produções textuais e pelo público destinatário. Esses textos já eram conhecidos pelos leitores dos jornais porto-alegrenses e pelo círculo mais restrito dos eruditos 
sul-rio-grandenses, mas o público que se buscava atingir privilegiadamente com essas reedições era o dos brasileiros de fora do estado. A palavra província identificava a origem da produção, mas não a da comunidade dos leitores, já que esta se pretendia expandir através do empreendimento editorial. As estratégias de inserção da revista no cenário cultural brasileiro permitem compreender algumas das possíveis ações dos intelectuais 'periféricos', em busca de sua legitimidade nos espaços políticos e culturais nacionais de consagração intelectual. Nesse sentido, cabe lembrar o que Moysés Vellinho ressaltou acerca da ideia que deu origem à publicação:

A Província teve origem numa conversa um tanto casual do Henrique Bertaso com o Gilberto Freyre. Eles falavam na criação de uma revista que seria um eixo de ligação entre o Rio Grande e Pernambuco. Isso interessava-nos especialmente por ter Pernambuco sido um dos estados que mais desenvolvera a pesquisa cultural e regional. Isso seria lá por 1943, mas uma série de fatores acabará impedindo a concretização imediata da ideia (Vellinho, 6 jan.1979).

A proeminência da cultura regional em Pernambuco direcionava esse estado a unir forças com o Rio Grande do Sul na busca por legitimar a produção cultural feita fora do eixo Rio-São Paulo. A busca da sobrevivência dos intelectuais com base no labor intelectual desvinculado, ao menos em aparência, da mácula das injunções político-partidárias e do mecenato governamental requeria alianças com os eventuais competidores nordestinos (Nedel, 2007). Foi assim que Vellinho reestruturou sua atuação intelectual: de posse de um emprego público que ele considerava apartidário, à frente de uma revista deficitária, que ele qualificava também como apartidária. O que no crítico ficava no discurso, entretanto, no romancista se concretizava, antes por sua experiência no contato com o lado comercial da Editora do Globo do que pela atuação política. Contudo, se as trajetórias de Veríssimo e Vellinho são distintas, podem também ser vistas como complementares, pois a editora que tinha prejuízo (ou não tinha lucro imediato) com a revista dirigida pelo segundo era a mesma que lucrava com a literatura do primeiro.

\section{A trama entre a província e a nação e a busca de legitimação da produção cultural sul-rio-grandense}

Dois anos após a volta dos EUA, em 1947, Veríssimo iniciou a escrita da trilogia que seria aclamada pela crítica local como sua grande obra. Na década de 1970, Veríssimo rememorava suas intenções ao planejar $O$ tempo e o vento: estava cansado da versão escolar da história gaúcha e sentia necessidade de desmitificá-la (Veríssimo, 1995, p.289). O sentido dessa 'desmitificação', entretanto, deve ser compreendido conforme categorias partilhadas na especificidade histórica dos anos 1940, em lugar de identificá-la exclusivamente com a denúncia do herói sul-rio-grandense construído pelo romantismo e pelo regionalismo locais. ${ }^{17}$ É necessário atentar para outro sentido, que é conferido pelo próprio autor à operação de desmitificação em $O$ tempo e o vento: ao retirar as máscaras dos heróis e dos homens rio-grandenses e humanizá-los, isto é, dar-lhes verossimilhança, tornava-os passíveis de serem perdoados por suas imperfeições e, dessa forma, de serem amados. Ainda sobre os 
motivos que o levaram a embarafustar pela temática da formação do Rio Grande do Sul desde os tempos heróicos, de forma irônica Veríssimo afirmou:

\begin{abstract}
Antes de começar o "ambicioso" projeto, eu precisava vencer muitas resistências interiores, a maioria delas originada nos meus tempos de escola primária e ginásio. Para o menino e para o adolescente - ambos de certo modo sempre presentes no inconsciente do adulto-, o poético e o novelesco eram atributos que raramente ou nunca se encontravam em pessoas, paisagens e coisas do âmbito nacional e muito menos do regional e ainda menos do municipal. Nossos livros escolares - feios, mal impressos em papel amarelado e áspero nunca nos fizeram amar ou admirar o Rio Grande e sua gente. Redigidos em estilo pobre e incolor de relatório municipal, eles nos apresentavam a história do nosso estado como uma sucessão aborrecível de nomes de heróis e batalhas entre tropas brasileiras e castelhanas. (Ganhávamos todas) (Veríssimo, 1995, p.289; grifos meus).
\end{abstract}

A insuficiente estima do autor com relação 'a sua gente' relacionava-se também com a conflituosa vida familiar pregressa de Veríssimo. Através da reencenação parcial das relações com seu pai em $O$ arquipélago, terceira parte de $O$ tempo e o vento, o escritor buscava compreendê-lo, marcar diferença em relação a ele, perdoá-lo e, por fim, amá-lo:

Para mim uma das partes mais importantes de $O$ arquipélago seria o momento em que Floriano, depois de um grande esforço sobre si mesmo, consegue entabular com Rodrigo, seu pai, um diálogo que eu gostaria de ter tido com o meu próprio pai: um "ajuste de contas" no plano sentimental, numa completa libertação de todas as mitologias, de todos os códigos escritos ou não, um encontro no plano humano da mútua aceitação e do amor (Veríssimo, 1997a, p.16, grifos meus).

As suas relações com o estado natal estiveram muito permeadas não apenas pela referência paterna, mas também por outras memórias familiares. Ao relatar a inspiração suscitada por um de seus parentes à construção de um personagem da trilogia, Érico rememorou a súbita ideia que se revelava a seus olhos e enfatizou sua resistência de longa data em tomá-los como objeto de sua obra ficcional - marcada, até então, quase exclusivamente pela temática urbana, pela rejeição à violência e pelo estilo de vida intelectualizado, que o distanciavam afetivamente de boa parte de seus ancestrais, ligados à vida rural: "Idiota! Como era que eu não tinha visto antes toda essa riqueza? E que dizer de Nico Velho, Aníbal Lopes, Nestor Veríssimo e cem outros varões? Era o meu povo, era o meu sangue. Eram as minhas vivências, diretas ou indiretas, que por tanto tempo eu renegara" (Veríssimo, 1995, p.292).

Chega-se assim a outro ponto fundamental de proximidade entre Vellinho e Veríssimo, frequentemente obliterado pela ênfase na manifestação de Veríssimo pela 'desmitificação' da história sul-rio-grandense. Mesmo que suas proposições quanto ao conteúdo da identidade regional apresentassem diferenças ${ }^{18}$, ambos partilhavam o diagnóstico da necessidade de incrementar em seus leitores o sentimento afetivo pela província natal: Vellinho desde os anos 1920, e Veríssimo, em especial, após seu 'trabalho de memória' individual e coletiva em O tempo e o vento. ${ }^{19}$

A despeito das repetidas afirmações de Veríssimo de que $O$ tempo e o vento não era um romance histórico nem regionalista - porque ele não tinha aptidão para historiador nem para a literatura regionalista (Veríssimo, 1997d) -, a trilogia, em especial sua primeira 
parte, $O$ continente, parece ter desfrutado, mais do que outros, da autonomia que um texto assume depois de sua publicação. ${ }^{20}$ À revelia das intenções manifestas de seu autor, o romance foi recebido pela crítica e pelo público local como um amplo "painel da história" sul-rio-grandense (Vellinho, 2001b), que testemunhava tanto as agruras quanto os sucessos dos tempos heróicos da "formação do Rio Grande do Sul", e acabou sendo tomado como um romance regionalista, relacionado à preceptiva do modernismo brasileiro (Leite, 1978, p.242).

Dessa vez, satisfeito com a presença renovada dos elementos regionais em $O$ continente tendo em vista a "adequação entre assunto e estilo" que prescrevia desde os anos $1920^{21}$, Moysés Vellinho foi um dos que aclamaram o romance apontando como um de seus principais méritos justamente a imagem que ele oferecia da integração da história e cultura regionais com as nacionais (Vellinho, 2001b, p.131). A comparação de O tempo e o vento, incluindo os volumes que ele não analisou, com suas prescrições como crítico literário e ensaísta converge principalmente na relação de continuidade que estabelece entre passado e presente, e no otimismo referente à modernização, anteriormente vista por Alcides Maya como um dos fatores desagregadores do caráter do gaúcho. Nessa nova configuração permaneciam traços fundamentais do tipo social do gaúcho desde os tempos da formação até os dias atuais, associados ao caráter heróico e bravo do sul-rio-grandense, mas em Veríssimo ineditamente associados à perseverança e ao pragmatismo das mulheres e à intelectualização e pacificação da índole masculina. Sendo assim, a progressiva descoloração da paisagem campestre, rural e guerreira do Rio Grande do Sul não era vista com pessimismo, mas sim como sinal de novos e promissores tempos (Leite, 2000). A 'cor local', obsessão da literatura romântica e nacionalista desde o século XIX, deveria ser obtida sob outros matizes. ${ }^{22}$

\section{Conclusão}

Ironicamente, a expectativa por uma viva representação da formação histórico-social da região, associada à emulação da afetividade pela terra natal já eram apresentadas de forma muito semelhante em 1923 pelo próprio Alcides Maya, quando incentivava Rubens de Barcellos a escrever um ensaio sobre o assunto. No final da carta que iniciara declarando ter-se tornado novelista "por amor" da "nossa terra e da nossa gente", o ícone do regionalismo que Veríssimo e Vellinho combatiam, declarava: "Verás como, fora das cronologias, das taxinomias, e das heroicidades oficiais, surgirá da tua pena um Rio Grande vivo, um Sul do Brasil palpitante, estuante, obra ao mesmo tempo do pensador e do artista! Não há ninguém na tua geração, como tu, para esse trabalho" (Maya, 1946, p.154).

Sob essa perspectiva, aqueles que ambicionavam renovar o regionalismo gaúcho eram herdeiros não apenas do próprio Alcides Maya, como também do romantismo do Partenon Literário, do século XIX. A motivação do amor pelo Rio Grande como ponto de partida para a representação poética e erudita, e a oscilação entre a afirmação da brasilidade do sul-rio-grandense e a reivindicação de uma cultura particular eram dois topos de longa duração nas práticas culturais regionais.

Assim, cabe questionar qual seria a distinção das proposições de Vellinho e Veríssimo na sucessão contraditória dos regionalismos gaúchos desde o século XIX. O que se percebe, 
principalmente no âmbito das estratégias narrativas, é que nos dois autores a cultura local era concebida como 'organicamente' ligada à nacional, e suas diferenças históricas recíprocas, como peculiaridade da primeira em relação à segunda. ${ }^{23} \mathrm{~A}$ província não podia ser considerada, tal como no século XIX, um pedaço que completaria, por colagem e adição, o quadro da história do Brasil. ${ }^{24}$ Para Veríssimo e, principalmente, para Vellinho, as histórias do Rio Grande do Sul e do Brasil, mais do que ficarem incompletas, não teriam lógica se não fossem compreendidas de modo entrelaçado. Na metáfora utilizada por Nedel (2005, p.273-274), a diferença entre uma e outra construção seria comparável àquela entre o mosaico estático e a dinâmica do caleidoscópio.

Em outros termos, pode-se pensar esses problemas teóricos da representação regional como decorrentes da passagem de uma história magistra vitae para uma concepção moderna de história (Koselleck, 1993). Contudo, o declínio da história exemplar e o aparecimento da ideia moderna de organicidade e processualidade na história regional podem ter sido configurados antes, com a escrita de Alfredo Varella, como sugerem estudos recentes (Silva, 2009). O problema, para esses autores, era denunciar a narrativa sem lógica da história regional apartada da história nacional e tecê-la novamente, reatando a trama narrativa entre a província e a nação. Além disso, a associação entre o estilo da escrita literária, os procedimentos acadêmicos da citação bibliográfica e de fontes primárias e o uso das categorias sociológicas inspiradas por Gilberto Freyre faria de Moysés Vellinho um dos representantes do ensaísmo brasileiro no Rio Grande do Sul. ${ }^{25}$

Em suma, a construção da brasilidade do gaúcho desde a década de 1930, bem como a filiação de Veríssimo e Vellinho a esse processo sofreram de forma crescente a intervenção de problemas estéticos e epistemológicos, em especial a partir da queda do Estado Novo, ao contrário do que afirmou a historiografia crítica sul-rio-grandense dos anos 1980, que classificou a escrita de Vellinho sobretudo pelo viés ideológico, em procedimento semelhante à "construção sociológica da posição regionalista de Gilberto Freyre", operada, principalmente, pela sociologia paulista uspiana (Sorá, 1998). ${ }^{26}$ Assim, um dos principais indícios da modernização cultural em curso na metade dos anos 1940 no estado sulino era a progressiva dissociação entre o regionalismo político e o regionalismo literário.

\section{NOTAS}

${ }^{1}$ A palavra local será utilizada neste texto como sinônimo de regional ou sul-rio-grandense.

${ }^{2}$ Em 1938 Érico Veríssimo lançou o romance Olhai os lírios do campo, que obteve enorme sucesso de vendas em todo o país, o que lhe possibilitou passar a viver dos ganhos obtidos na literatura (Veríssimo, 1995, p.268-269).

${ }^{3}$ Este é o caso, por exemplo, de dois estudos muito conhecidos que influenciaram uma série de trabalhos no Brasil: Pécaut, 1990 e Miceli, 1979.

${ }^{4}$ François Hartog (1999) e Reinhart Koselleck (2004), por exemplo.

${ }^{5}$ Como exemplo de abordagem que supera a dualidade texto/contexto para os intelectuais brasileiros do período que aqui interessa, pode-se citar, em especial, o trabalho de Ângela Castro Gomes (1993).

${ }^{6}$ Como os de Letícia Nedel (2005; 2007) e Odaci Coradini, (2003), para o contexto sul-rio-grandense, e o de Albuquerque Jr. (2001), para a 'invenção do Nordeste'.

${ }^{7}$ A proposição da ensaística brasileira como 'lugar' epistemológico de escrita parte aqui da discussão sobre a inserção de Casa Grande \& Senzala na cultura escrita brasileira, desenvolvida na tese de Fernando Nicolazzi (2008, p.307-369). Ver também Sorá, 1998. 
${ }^{8}$ A obra que notabilizou Moysés Vellinho como historiador, Capitania D’El Rey (1964), aproxima-se em muitos aspectos da representação regional configurada por Érico Veríssimo em O tempo e o vento. Sobre esse paralelo, ver Rodrigues (2006). Sobre o envolvimento de Moysés Vellinho com a revolução de 1930, ver depoimento cedido pelo escritor ao CPDOC no final da década de 1970 (Vellinho, 1981b).

${ }^{9}$ Este subtítulo e a narrativa que se segue fazem referência às noções forjadas por Norbert Elias (2003) sobre a frequente distinção de uma aristocracia territorial e simbolicamente estabelecida em contraposição aos forasteiros.

${ }^{10}$ Sobre o papel da Editora do Globo na vida intelectual e cultural dos anos 1930 no Rio Grande do Sul, ver Miceli, 1979.

${ }^{11}$ Conforme Elias (2003), as vestimentas serviam como signos de distinção e poder, e o sentimento de inferioridade pode partir do próprio outsider, quando defrontado com o 'estabelecido'.

${ }^{12}$ A polêmica entre Vellinho (Paulo Arinos) e Barcellos é bem conhecida dos historiadores da literatura sul-rio-grandense. Ver, entre outros, Chaves, 1979. Os textos da polêmica desenvolvida no Correio do Povo, em 1925, foram publicados em Baumgarten, 2001.

${ }^{13}$ Clarice Lispector perguntava a Veríssimo, em 1967: "Érico, por que você acha que não agrada aos críticos e aos intelectuais?" (Veríssimo, 1997c, p.19).

${ }^{14} \mathrm{O}$ romancista deu várias declarações condenando os autoritarismos políticos de esquerda e de direita. Ver, por exemplo, Veríssimo, 1997d.

${ }_{15}$ Alguns autores têm-se dedicado, com bons resultados, a estudar as relações entre a experiência da viagem e a da representação, como Wegner (2000), Cezar (2007) e Nicolazzi (2008). Pretende-se futuramente estudar de que forma as viagens de Veríssimo e Vellinho aos EUA lhes afetaram o trabalho de memória e a operação representacional.

${ }^{16}$ Um CD-ROM com catálogo e textos da Revista Província de São Pedro (1945-1957) foi organizado por Mottin et al. (1999).

${ }^{17}$ Como em Zilberman, 2004, para citar apenas um exemplo.

${ }^{18}$ Enquanto Vellinho negligenciava a importância das raízes indígenas do tipo social gaúcho, Veríssimo, ao contrário, situara as raízes da família Terra-Cambará no índio Pedro Missioneiro e na paulista e filha de tropeiros Ana Terra. Em Vellinho, os heróis eram, sobretudo, os desbravadores portugueses, enquanto em Veríssimo, ineditamente, as mulheres detinham essa qualidade (Athayde, 1972).

${ }^{19}$ Refiro-me aqui à dimensão terapêutica do trabalho de memória, conforme propõe Ricouer (2000, p.735), no sentido de evitar os abusos da memória (manipulada, impedida e obrigada).

${ }^{20}$ Segundo Paul Ricouer (1990, p.53), os textos devem ser compreendidos como órfãos, porque independentemente das intenções dos autores, os significados a ele atribuídos estão relacionados a sua recepção e não a sua produção. Apesar de não considerarmos essa fórmula universalmente aplicável para a compreensão do sentido de um texto, ela nos parece fértil, uma vez que podemos pensar em uma certa autonomia do texto, sem o desvincular totalmente do processo de produção.

${ }^{21}$ Ligia Chiappini Leite (1978, p.119) reforçou a condenação de Vellinho (2001a) do regionalismo de Maya, ressaltando o efeito de distanciamento criado pela linguagem dual que separava claramente o narrador erudito de seu objeto, o homem rústico.

${ }^{22}$ Sobre a noção de 'cor local' nas narrativas sobre a nação no século XIX, ver Cezar, 2004.

${ }^{23}$ Sobre a tensão entre a inserção e distanciamento da identidade cultural sul-rio-grandense em relação ao Brasil ver Oliven, 1992.

${ }^{24}$ Luciana Boeira (2009) demonstrou a presença tópica da brasilidade do Rio Grande do Sul, na história exemplar escrita pelos intelectuais do Partenon Literário no Rio Grande do Sul do século XIX.

${ }^{25}$ Sobre a recepção de Gilberto Freyre no Rio Grande do Sul, ver Nedel, 2007. Sobre a importância de Freyre na obra de Vellinho, ver Rodrigues, 2006, p.154-218.

${ }^{26}$ Para um contraponto de algumas interpretações da autodenominada historiografia crítica dos anos 1980 no que diz respeito ao Rio Grande do Sul, no período entre os anos 1930-1950, ver Nedel e Rodrigues, 2005. 


\section{REFERÊNCIAS}

ALBUQUERQUE JÚNIOR, Durval Muniz. A invenção do Nordeste e outras artes. Recife: Massangana. 2001.

ATHAYDE, Tristão.

Érico Veríssimo e o antimachismo. In: Chaves, F.L. (Org.). O contador de histórias: 40 anos de vida literária de Érico Veríssimo. Porto Alegre: Globo. p.86-102. 1972.

BAUMGARTEM, Carlos Alexandre (Org.). Ensaios literários: Moysés Vellinho. Porto Alegre: IEL; Corag. 2001.

BOEIRA, Luciana.

Entre a história e a literatura: a formação do Panteão Rio-grandense e os primórdios da escrita da história no Rio Grande do Sul no século XIX. Dissertação (Mestrado em História) - Instituto de Filosofia e Ciências Humanas, Universidade Federal do Rio Grande do Sul, Porto Alegre. 2009.

CERTEAU, Michel de.

A escrita da história. Rio de Janeiro: Forense Universitária. 2002.

CEZAR, Temístocles.

Varnhagen em movimento: breve antologia de uma existência. Topoi, Rio de Janeiro, v.8, n.15, p.159-207. 2007.

CEZAR, Temístocles.

Narrativa, cor local e ciência: notas para um debate sobre o conhecimento histórico do século XIX. História UNISINOS, São Leopoldo, v.8, n.10, p.11-34. 2004.

CHARTIER, Roger.

A história entre narrativa e conhecimento. In: Chartier, Roger. À beira da falésia: a história entre certezas e inquietude. Porto Alegre: Editora da UFRGS. p.81-100. 2002.

CORADINI, Odaci Luiz.

As missões da cultura e da política: confrontos e reconversões de elites culturais e políticas no Rio Grande do Sul (1920-1960). Estudos Históricos, Rio de Janeiro, n.32, p.125-144. 2003.

ELIAS, Norbert.

Ensayo acerca de las relaciones entre establecidos y forasteros. Reis: Revista Española de Investigaciones Sociológicas, Madrid, n.104, p.219-251. Disponível em: http:// dialnet.unirioja.es/servlet/articulo?codigo $=$ 837509. Acesso em: 15 mai 2009. 2003.

GERTZ, René.

O ciclo Vargas segundo Veríssimo. In: Gonçalves, Robson (Org.). O tempo e o vento: 50 anos. Bauru: EdUSC. p.199-206. 2000.
GOMES, Ângela de Castro.

Essa gente do Rio... : os intelectuais cariocas e o modernismo. Estudos Históricos, Rio de Janeiro, v.6, n.11, p.62-77. 1993.

HARTOG, François.

O espelho de Heródoto: ensaio sobre a representação do outro. Belo Horizonte: Editora UFMG. 1999.

KOSELLECK, Reinhart.

História. Madrid: Trotta. 2004.

KOSELLECK, Reinhart.

História magistra vitae. In: Koselleck, Reinhart Futuro pasado. Barcelona: Paidós. p.41-66. 1993.

LAJOLO, Marisa.

Uma trajetória rara na tradição cultural brasileira. Letras Hoje, Porto Alegre, v.20, n.3, p.165-176. 1986.

LEITE, Lígia Chiappini Moraes.

Campo e cidade em O retrato. In: Pesavento, Sandra (Org.). Leituras cruzadas: diálogos da história com a literatura. Porto Alegre: Editora da UFRGS. p.49-72. 2000.

LEITE, Lígia Chiappini Moraes.

Regionalismo e modernismo: o caso gaúcho. São Paulo: Ática. 1978.

MAYA, Alcides.

[Sem título]. Província de São Pedro, Porto Alegre, v.2, n.7, p.153-154. 1946.

MICELI, Sérgio.

Intelectuais e classe dirigente no Brasil: 1920-1945. Rio de Janeiro: Difel. 1979.

MILLIET, Sérgio.

[Sem título]. Província de São Pedro, Porto Alegre, v.2, n.4, p.14. 1946.

MOREIRA, Maria Eunice.

No princípio é silêncio. Letras Hoje, Porto Alegre, v.20, n.3, p.101-112. 1986.

MOTTIN, Antônio et al. Revista Província de São Pedro (1945-1957): catálogo e texto. Porto Alegre: PUCRS. CD-ROM. 1999.

NEDEL, Letícia Borges.

A recepção da obra de Gilberto Freyre no Rio Grande do Sul. Mana, Rio de Janeiro, v.13, n.1, p.85-118. 2007.

NEDEL, Letícia Borges.

Um passado novo para uma história em crise: regionalismo e folcloristas no Rio Grande do Sul (1948-1965). Tese (Doutorado em História) - Instituto de Ciências Sociais, Universidade de Brasília, Brasília. 2005. 
NEDEL, Letícia Borges; RODRIGUES, Mara Cristina de Matos.

Historiografia, crítica e autocrítica: itinerários da história no Rio Grande do Sul. Agora, Santa Cruz do Sul, v.11, n.1, p.161-186. 2005.

NICOLAZZI, Fernando Felizardo.

Um estilo de história: a viagem, a memória, o ensaio - sobre Casa-grande \& senzala e a representação do passado. Tese (Doutorado em História) - Instituto de Filosofia e Ciências Humanas, Universidade Federal do Rio Grande do Sul, Porto Alegre. 2008.

OLIVEN, Ruben George.

A parte e o todo: a diversidade cultural no Brasil-nação. Petrópolis: Vozes. 1992.

PÉCAUT. Daniel.

Os intelectuais e a política no Brasil: entre o povo e nação. São Paulo: Ática. 1990.

RICOUER, Paul.

La mémoire, l'histoire, l'oubli. Paris: Seuil. 2000.

RICOUER, Paul.

A função hermenêutica do distanciamento.

In: Ricouer, Paul. Interpretação e ideologias. Rio de Janeiro: Francisco Alves. p.43-60. 1990.

RODRIGUES, Mara Cristina de Matos. Da crítica à história: Moysés Vellinho e a trama entre a província e a nação, 1925 a 1964. Tese (Doutorado em História) - Instituto de Filosofia e Ciências Humanas, Universidade Federal do Rio Grande do Sul, Porto Alegre. 2006.

SILVA, Jaisson.

A epopéia dos titãs do pampa: historiografia e narrativa épica na História da Grande

Revolução, de Alfredo Varella. Dissertação (Mestrado em História) - Instituto de Filosofia e Ciências Humanas, Universidade Federal do Rio Grande do Sul, Porto Alegre. 2010.

SORÁ, Gustavo.

A construção sociológica de uma posição regionalista: reflexões sobre a edição e recepção de Casa Grande e Senzala de Gilberto Freyre. Revista Brasileira de Ciências Sociais, São Paulo, v.13, n.36. Disponível em: http://www.scielo.br. scielo.php?script=sci_arttext\&pid=S010269091998000100008. Acesso em: 17 jun. 2009. 1998.

TRINDADE, Fernando.

A polêmica entre Érico Veríssimo e o padre Leonardo Fritzen, S.J. Revista do IFCH - UFRGS, Porto Alegre, v.12, p.35-98. 1984.

VELLINHO, Moysés.

Alcides Maya: a expressão literária e o sentido sociológico de seu pensamento. In:
Baumgarten, Carlos A. (Org.). Moysés Vellinho: ensaios literários. Porto Alegre: IEL. p.73-89. 1.ed., 1944. 2001a.

VELLINHO, Moysés.

O tempo e o vento. In: Baumgarten, Carlos A. (Org.). Moysés Vellinho: ensaios literários. Porto Alegre: IEL. p.123-131. 1.ed., 1949. 2001b.

VELLINHO, Moysés.

Moisés Vellinho: depoimento, 1977. Rio de Janeiro: CPDOC - História Oral/Fundação Getulio Vargas. 1981a.

VELLINHO, Moysés.

Revolução de 30, em seu trigésimo aniversário (1960). In: Vellinho, Moysés.

Aparas do tempo. Porto Alegre: Cia. União de Seguros Gerais. p.119-128. 1981b.

VELLINHO, Moysés.

Um velho chefe de clã lusitano em terras gaúchas: entrevista a Antônio Hohfeldt. Correio do Povo, Porto Alegre, Caderno de Sábado. 6 jan. 1979.

VELLINHO, Moysés.

Capitania d'El Rey: aspectos polêmicos da formação rio-grandense. Porto Alegre: Globo. 1964.

VELLINHO, Moysés.

Editorial. Província de São Pedro, Porto Alegre, n.6, p.5-6. 1946a.

VELLINHO, Moysés.

Editorial. Província de São Pedro, Porto Alegre, n.5, p.6-7. 1946b.

VERÍSSIMO, Érico.

Solo de Clarineta II. 10.ed. São Paulo: Globo. 1997a.

VERÍSSIMO, Érico.

O resto é silêncio. 22.ed. São Paulo: Globo. 1.ed.,1943. 1997b.

VERÍSSIMO, Érico.

Não sou profundo: entrevista a Clarice Lispector. In: Bordini, Maria da Glória (Org.). A liberdade de escrever: entrevistas sobre literatura e política. Porto Alegre: Editora da UFRGS; PUCRS; Prefeitura Municipal de Porto Alegre. p.19-26. 1997c.

VERÍSSIMO, Érico.

A agulha e a bússola: entrevista concedida a Rosa Freire D'Aguiar. In: Bordini, M.G. (Org.). A liberdade de escrever. Porto Alegre: Editora da UFRGS; PUCRS; Prefeitura Municipal de Porto Alegre. p.133-150. 1997d.

VERÍSSIMO, Érico.

Solo de Clarineta I. 20.ed. São Paulo: Globo. 1995. 
Mara Cristina de Matos Rodrigues

WEGNER, Robert.

A conquista do Oeste: a fronteira na obra de Sérgio Buarque de Holanda. Belo Horizonte: UFMG. 2000.
ZILBERMAN, Regina.

História, mito e literatura. In: Bordini, Maria da Glória; Zilberman, Regina. O tempo e o vento: história, invenção e metamorfose. Porto Alegre: EdiPUCRS. p.21-48. 2004.

\section{$\rightarrow \rightarrow \rightarrow<<<$}

